CARADDE: Jurnal Pengabdian Kepada Masyarakat
institute
Volume 1 / Nomor 1 I Agustus | 2018
e-ISSN: 2621-7910 dan p-ISSN: 2621-7961
DOI: https://doi.org/10.31960/caradde.v1i1.2

\title{
Psikoedukasi Siswa Mengenai Quality of School Life
}

\author{
Riana Sahrani ${ }^{1}$, Rahmah Hastuti ${ }^{2}$
}

\begin{tabular}{ll}
\hline \hline Keywords: & Abstrak. Tujuan kegiatan pengabdian pada masyarakat ini adalah \\
Kualitas kehidupan sekolah; & untuk mendapatkan wawasan dalam rangka membangun \\
Psikoedukasi; & pemahaman tentang kualitas kehidupan sekolah. Kegiatan ini \\
Siswa & dilakukan pada siswa MTs X Jakarta Barat. Layanan masyarakat \\
& ini didasarkan pada keluhan dari kepala sekolah yang menilai \\
Corespondensi Author & perlunya bimbingan yang diberikan kepada siswa di sekolah, yang \\
Fakultas Psikologi, Universitas & diadakan pada 6 November 2017. Kegiatan ini melibatkan 31 siswa \\
Tarumanagara Jakarta & dari kelas 9. Berdasarkan hasil analisis dapat disimpulkan bahwa \\
Alamat Penulis & tidak ada perbedaan ditemukan antara siswa laki-laki dan \\
Email: rianas@fpsi.untar.ac.id \& & perempuan terkait persepsi kualitas kehidupan sekolah secara umum, \\
rahmahh@fpsi.untar.ac.id & prestasi, integrasi sosial, peluang dan petualangan di sekolah. Mereka \\
& merasa puas setelah program psikoedukasi dilaksanakan.
\end{tabular}

Received: Juni-2018;

Reviewed: Juli-2018

Accepted: Juli-2018

Published: Agustus-2108

This work is licensed under a Creative Commons Attribution

4.0 International License

\section{PENDAHULUAN}

Kegiatan Pengabdian Kepada
Masyarakat (PKM) ini dilaksanakan pada
siswa Madrasah Tsanawiyah (MTs) yang
setara dengan SMP, di Madrasah X
Jakarta Barat. PKM ini didasari atas
permintaan kepala sekolah dan guru yang
menilai perlunya diberikan pengarahan bagi
siswa-siswi di sekolahnya, terkait dengan
pengalaman positif bagi siswa-siswinya yang
dapat memperkaya proses pembelajaran bagi
siswa. Dalam setting sekolah, guru selaku
pendidik mem-berikan kesempatan para siswa
untuk dapat belajar secara mandiri, namun
guru juga mengharapkan adanya bekal strategi
yang memperkaya belajar siswa untuk dapat
mencapai tujuan belajarnya (freedom to explore
and learn within clear goals). Bagi peserta didik
yang merupakan peserta dalam psikoedukasi

ini diharapkan dapat memperoleh insight untuk dapat memperoleh pemahaman serta keterampilan baru yang dapat menjadi life skills intervention.

Adapun tujuan dan manfaat kegiatan ini adalah agar dapat memberikan gambaran secara empiris dan ilmiah mengenai persepsi siswa mengenai sekolahnya. Dalam PKM ini juga dilakukan uji pre-test dan dilanjutkan dengan materi mengenai Psikoedukasi terkait dengan Quality of School Life. Setelah pemberian materi maka dilakukan post-test. Analisis data dilakukan dengan software PASW18. Teknik paired sample t-test digunakan untuk melihat keefektifan sosialisasi atau pendampingan dalam kegiatan pengabdian di lokasi sekolah mitra tersebut. Selain itu dengan kegiatan PKM ini diharapkan dapat membantu memberikan solusi atas permasalahan yang dihadapi oleh mitra. Pengabdian kepada Masyarakat ini ditujukan 
untuk menjawab permasalahan yang dipersepsi oleh guru-guru terhadap para siswa di MTs X tersebut, berdasarkan informasi terkait kebutuhan psikoedukasi secara psikologis.

Pelaksanaan kegiatan ini dilakukan secara interaktif dan dialogis agar dapat diperoleh gambaran umum mengenai pengalaman positif di siswa sekolah, khususnya di MTs X. Dialog interaktif ini dilakukan terhadap para siswa-siswi kelas 9. Setelah mendapatkan gambaran pengalaman positif di sekolah yang lebih detail, kemudian inventori diberikan kepada peserta. Peserta mengisi kuesioner pengalaman positif di sekolah.

Setelah terkumpul semua jawaban maka dilakukan analisis data (skor rerata) respon partisipan. Metode ceramah mengenai pengalaman positif di sekolah dan kaitannya dengan situasi dan lingkungan pembelajaran di MTs X. Peserta diberikan pengenalan mengenai suasana belajar yang menyenangkan di MTs X, sehingga lebih mampu meningkatkan persepsi positif mengenai kualitas kehidupan bersekolah di MTs X. Secara umum, kegiatan ini menggunakan metode ceramah, dan workshop dalam identifikasi pengalaman positif di sekolah, bagi siswa di MTs, serta penggunaan self-report dalam bentuk skala psikologi.

Adapun kegiatan PKM ini memiliki target khusus, yaitu: (1) dapat memberikan gambaran secara empiris dan ilmiah aspek psikologis siswa terkait dengan pengalaman positif di sekolah, khususnya di MTs X. (2) meningkatkan pengetahuan serta keterampilan siswa di MTs X melalui psikoedukasi dengan tujuan memberikan life skills intervention.

Teori-teori yang dipakai dalam penulisan hasil pengabdian masyarakat ini adalah mengenai psikoedukasi dan quality of school life. Definisi dari istilah psikoedukasi adalah suatu intervensi yang dapat dilakukan pada individu, keluarga, dan kelompok yang fokus pada mendidik partisipannya mengenai tantangan signifikan dalam hidup, membantu partisipan mengembangkan sumber-sumber dukungan dan dukungan sosial dalam menghadapi tantangan tersebut, dan mengembangkan keterampilan coping untuk menghadapi tantangan tersebut. Psikoedukasi adalah treatment yang diberikan secara profesional mengintegrasikan intervensi psikoterapeutik dan edukasi (Lukens \& McFarlane, 2004).
Selaras dengan kondisi tersebut, alasan mengapa pandangan siswa mengenai sekolah adalah suatu hal yang penting karena siswa menghabiskan bagian penting dari kehidupan mereka di sekolah dan tentunya dianggap memengaruhi belajar siswa ("School Life Questionnaire, n.d). Pemikiran siswa mengenai sekolah mereka adalah topik yang sering menjadi percakapan antara siswa sendiri, antara siswa dan keluarga mereka dan di antara guru. Bahkan, meningkatkan kualitas pendidikan merupakan fokus utama dari negara-negara di Barat sejak tahun 1800an (Esptein; Ainley, Reed \& Miller; Huges dikutip dalam Sun-Keung, 1999). Tidak dapat dipungkiri bahwa pendidikan memainkan peran yang menentukan untuk kualitas hidup di masa dewasa. Orang biasanya mengasosiasikan kualitas pendidikan dengan keberhasilan di sekolah. Namun, kurang diperhatikan bahwa ada aspek lainnya yang tidak kalah penting yaitu kesenangan yang didapat dari belajar, berbagi pengalaman dan kesuksesan, dan aspek-aspek pribadi yang menyenangkan lainnya dari kehidupan sekolah yang membentuknya.

Salah satu penelitian spesifik yaitu mengenai kualitas hidup yang berhubungan dengan atmosfer sekolah. Inilah pandangan awal mengenai penelitian terkait dengan quality of school life. Penelitian mengenai kualitas kehidupan sekolah yang pernah dilakukan terkait dengan kepuasan sekolah. Sebagian besar penelitian di bidang ini lebih menggunakan variabel sosiologis dalam paradigma penelitian yang pernah dilakukan oleh Guthrie (dikutip dalam Hurley \& Bulcock, 2012) yang pernah mengembangkan penelitian di bidang keuangan pendidikan. Hasil penelitian sebelumnya dari Williams (dikutip dalam Hurley \& Bulcock, 2012), yang mengkaji mengenai quality of school life menghasilkan temuan empiris bahwa beberapa siswa mengakui bahwa sekolah mereka sebagai bagian dari hidup, menilai sekolah sebagai tempat yang menggembirakan, sedangkan untuk yang lain sekolah adalah menyedihkan, tempat yang menimbulkan perasaan tidak bahagia. Sekolah merupakan insititusi pendidikan yangg menyelenggarakan jenjang pendidikan formal yang meliputi pendidikan dasar, pendidikan menengah, dan pendidikan tinggi. Di Indonesia bentuk 
pendidikan dalam tiap jenjang terdiri atas sekolah negeri dan sekolah swasta.

Berdasarkan hasil penelitian yang dilakukan oleh Ainley, Foreman, dan Sheret (1991) di Australia mengenai High School Factors That Influence Students to Remain in School, diperoleh hasil bahwa sebagian besar siswa di negara maju menghabiskan setidaknya sepuluh tahun hidup mereka di sekolah. Hal ini menjadi tolok ukur sikap siswa terhadap sekolahnya terjalin hubungan yang positif atau tidak dalam mengikuti kegiatan tersebut dan memengaruhi untuk melanjutkan ke sekolah berikutnya. Kehidupan sekolah adalah persiapan untuk partisipasi sosial di masa depan.

Sekolah merupakan bagian integral yang tidak dapat dipisahkan dari kehidupan seorang anak sebagai siswa. Oleh karena itu, kualitas kehidupan sekolah atau quality of school life merupakan bagian penting dari kualitas hidup secara keseluruhan yang dialami oleh seorang anak. Hal tersebut merupakan hasil kajian dari

\section{METODE}

Hal pertama yang dilakukan yaitu observasi ataupun studi pendahuluan terhadap siswa melalui diskusi dengan para guru serta kepala sekolah. Setelah itu, narasumber memberikan materi strategi meningkatkan pengalaman positif di sekolah melalui pengenalan konsep
Ghotra et al. (2016) di Kanada mengenai kualitas kehidupan sekolah. Penelitian oleh Ghotra et al. (2016) berjudul Validation of the Quality of Life in School Instrument in Canadian Elementary School Student, yang melibatkan sekolah dasar umum dan asrama kelas 4 sampai 6 di usia 9 sampai 12 tahun. Penelitian tersebut menggunakan alat ukur The Quality of Life in School (QoSL).

Dalam kegiatan PKM ini, alat ukur yang digunakan yaitu The Quality of School Life Scale (QoSL) yang merupakan instrumen ukur yang dirancang untuk mengukur persepsi siswa terhadap pengalamannya selama di sekolah. Alat ukur tersebut digunakan untuk mengukur variabel quality of school life yang akan diterjemahkan ke dalam Bahasa Indonesia. Alat ukur ini menggunakan skala Likert yang terdiri dari 4 skala dari 1 (sangat tidak setuju) sampai 4 (sangat setuju). Alat ukur ini terdiri dari tujuh dimensi.

quality of school life. Setelah pemberian materi dilakukan pengukuran melalui self-report dengan menggunakan kuesioner. Kegiatan PKM dilakukan pada 31 partisipan.

Tabel 1. Gambaran Partisipan PKM Berdasarkan Jenis Kelamin

\begin{tabular}{clrr}
\hline No & \multicolumn{1}{c}{ Jenis Kelamin } & Jumlah & \multicolumn{2}{c}{ Persentase } \\
\hline 1 & Laki-laki & 15 & 48,4 \\
2 & Perempuan & 16 & 51,6 \\
\hline \multicolumn{2}{l}{ Total } & 31 & 100,0 \\
\hline
\end{tabular}

\section{HASIL DAN PEMBAHASAN}

Desain program pengabdian kepada masyarakat ini adalah one group posttest only. Analisis kuantitatif deskriptif dilakukan dengan bantuan program SPSS 24. Peserta yang mengisi kuesioner kualitas kehidupan sekolah terdiri dari 31 partisipan yang terdiri dari 16 perempuan $(51.6 \%)$ dan laki-laki sebanyak 15 orang (48.4\%). Secara terperinci, skor rata-rata kepuasan secara umum partisipan sesudah diberikan materi adalah sebesar $\mathrm{M}=3.1989, \mathrm{SD}=0.345$. Hal ini berarti bahwa perasaan positif siswa terhadap sekolah adalah tinggi karena rerata yang diperoleh lebih besar dari nilai tengah skala yaitu sebesar 2.5. Skor rata-rata persepsi kualitas terhadap guru pasca pemberian materi adalah sebesar $\mathrm{M}$ $=3.135, \mathrm{SD}=0.373$. Guru dipersepsi oleh siswa sebagai agen yang adil, penolong, penuh perhatian. Skor rata-rata persepsi kualitas sekolah sebagai tempat pencapaian prestasi adalah sebesar $\mathrm{M}=3.397, \mathrm{SD}=0.388$. Skor rerata yang lebih besar dari nilai tengah skala 
Caradde: Jurnal Pengabdian Kepada Masyarakat

Vol 1 No 1, Agustus 2018

menunjukkan keyakinan siswa untuk menjadi suskes dalam belajar dan meraih masa depan yang baik. Perasaan negatif siswa terhadap sekolah memiliki skor rerata sebesar $\mathrm{M}=$ 3.045, $\mathrm{SD}=0.392$. Skor rerata yang lebih besar dari nilai tengah skala menunjukkan bahwa terkadang kualitas kehidupan di sekolah dipersepsi berpengaruh terhadap kesepian, mood negative, kecemasan dan kemarahan siswa. Persepsi siswa terhadap kualitas sekolah yang berfungsi sebagai integrasi sosial sebesar $\mathrm{M}=2.922, \mathrm{SD}=0.482$. Kualitas sekolah sebagai fasilitator kesempatan positif siswa memiliki skor rerata sebesar $\mathrm{M}=3.526, \mathrm{SD}=$
0.349. Kualitas aspek "petualangan"dalam kualitas kehidupan sekolah menurut siswa adalah baik karena skor rerata $\mathrm{M}=3.166$, $\mathrm{SD}=0.462$ yang lebih besar dari nilai tengah skala 2.5 .

Data yang diperoleh kemudian diuji normalitas sebarannya dengan menggunakan teknik Shapiro Wilk. Berdasarkan analisis ditemukan bahwa data terkait kualitas guru $(\mathrm{SW}=0.935, \mathrm{df}=31, \mathrm{p}=0.061)$ afek negative $(\mathrm{SW}=0.939, \mathrm{df}=31, \mathrm{p}=0.077)$, dan kualitas kehidupan sekolah ( $\mathrm{SW}=0.934$, $\mathrm{df}=31, \mathrm{p}=$ 0.057) berdistribusi normal. Berikut adalah tabel pengujian normalitas data.

Tabel 2. Uji Normalitas Data

\begin{tabular}{lcccccr}
\hline & \multicolumn{2}{c}{ Kolmogorov-Smirnov } & \multicolumn{3}{c}{ Shapiro Wilk } \\
& Statistik & df & sig & Statistik & df & sig \\
\hline General_satis & .247 & 31 & .000 & .853 & 31 & .001 \\
Teacher & .125 & 31 & $.200^{*}$ & .935 & 31 & .061 \\
Achievement & .211 & 31 & .001 & .887 & 31 & .004 \\
Negative_affect & .191 & 31 & .005 & .939 & 31 & .077 \\
Social_integration & .212 & 31 & .001 & .916 & 31 & .019 \\
Opportunity & .171 & 31 & .021 & .917 & 31 & .020 \\
Adventure & .223 & 31 & .000 & .912 & 31 & .015 \\
Kualitas_kehidupan_sekola & .128 & 31 & $.200^{*}$ & .934 & 31 & .057 \\
h & \multicolumn{7}{c}{} \\
\hline \multicolumn{7}{c}{ *. This is a lower bound of the true significance. } \\
\hline
\end{tabular}

a. Lilliefors Significance Correction

Adapaun mengenai perbedaan Kualitas Kehidupan Sekolah, berdasarkan hasil uji normalitas maka data variabel yang terdistribusi normal dapat dilakukan uji analisis perbedaan secara parametrik. Berdasarkan uji beda indepedent-T test diperoleh bahwa baik siswa laki-laki atau perempuan tidak memiliki pemahaman yang berbeda terhadap kualitas kehidupan sekolah, guru, dan afek negatif.

Demikian juga melalui uji beda dengan teknik statistik non-parametrik dengan MannWhitney tidak ditemukan perbedaan antara siswa laki-laki dan perempuan terkait persepsi terhadap kualitas kepuasan secara umum, prestasi, integrasi sosial, kesempatan dan petualangan di sekolah.

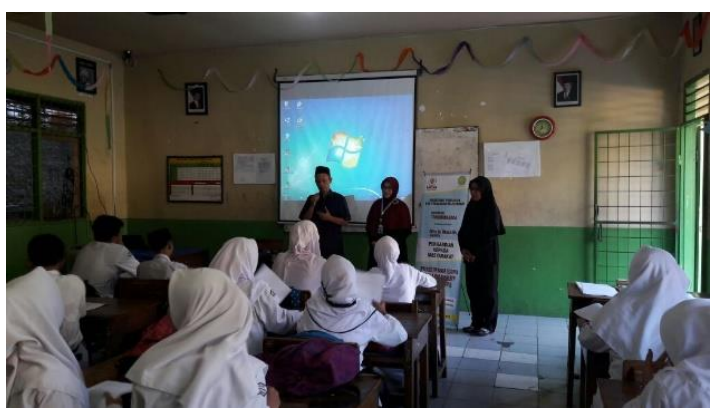

Gambar 1 Foto Kegiatan 
Tidak ditemukannya perbedaan antara siswa laki-laki dan perempuan terkait persepsi terhadap kualitas kepuasan secara umum, juga karena kepuasan hidup seorang siswa tergantung pada lima hal. Kelima hal tersebut adalah (1) keluarga, (2) teman, (3) sekolah, (4) diri sendiri dan (5) lingkungan (Seligson, Huebner \& Valois, dalam Saraswati, Tiatri, \& Sahrani, 2017). Jadi bagaimana seorang siswa merasa memiliki hubungan yang baik dengan rekan seusianya dan relasi baik dengan orangorang dewasa yang ada di sekolah juga merupakan hal yang paling dominan dalam memprediksi kepuasan hidup siswa tersebut (Gadermann et,al., 2016). Fasilitas sekolah juga berpengaruh terhadap kepuasan siswa di sekolah (Arifin, 2016; Sun-Keung, 1999), misalnya dari sekolah yang tadinya rusak kemudian diperbaiki menjadi baik kembali (Dorothy, Monika, \& Wijaya, 2018).

\section{SIMPULAN DAN SARAN}

Berdasarkan kegiatan yang telah dilakukan, dapat disimpulkan bahwa siswasiswi yang telah memberikan feedback melalui

\section{DAFTAR RUJUKAN}

Arifin, S. (2016). Hubungan Antara Kondisi Lingkungan Belajar di Sekolah dan Hasil Belajar IPA Siswa kelas V. Jurnal pendidikan guru sekolah dasar. (Ed) 34, tahun ke-5.

Dorothy, G. P., Monika, \& Wijaya, E. (2018). Persepsi Siswa terhadap Quality of School Life pada Sekolah yang Pernah Mengalami Kondisi Rusak Fisik (Studi Kasus pada SDN X di Jakarta). Provitae Jurnal Psikologi Pendidikan,11(1), 84 - 104

Gadermann, A. M., Guhn, M., SchonertReichl, K. A., Hymel, S., Thomson, K. \& Hertzman, C. (2016). A population-based study of children's well-being and health: The relative importance of social relationships, Health-Related Activities, and Income. Journal of Happiness Studies, 17, 1847-1872. doi: 10.1007/s10902-0159673-1 hasil evaluasi self-report yang dianalisis secara statistik, menyatakan bahwa siswa-siswi mendapatkan manfaat dari kegiatan tersebut. Oleh karena sesi psikoedukasi hanya berupa ceramah sehingga hanya mengena pada aspek kognitif serta afeksi dan belum merubah perilaku. Namun demikian, berdasarkan hasil pengolahan dan analisis data secara statistik, tidak ditemukan perbedaan antara siswa lakilaki dan perempuan terkait persepsi terhadap kualitas kepuasan secara umum, prestasi, integrasi sosial, kesempatan dan petualangan di sekolah.

Seperti yang terlihat dari hasil psikoedukasi dalam laporan abdimas ini, ada beragam metode untuk menilai persepsi, masing-masing dengan kekuatan dan keterbatasan dan berguna untuk tertentu tujuan. Namun, bahkan saat survei berupa selfreport, nampak ada variasi dalam persepsi terkait kualitas lingkungan kehidupan sekolah menurut para siswa. Pada umumnya, abdimas ini dapat menjadi saluran untuk membagikan informasi untuk meningkatkan wawasan pengetahuan, khususnya bagi setiap pihak yang memerlukan.

Hurley, N. P. \& Bulcock, J. (2012). Measurement models of the quality of school life. Retrieved from http://www.mun.ca/educ/faculty/mwat ch/Hurley\%20\&\%20Bulcock\%20Measure ments $\% 20$ Final $\% 20$ Nov_\%2014, $\% 202012$ .pdf

Sun-Keung, N. P. (1999). Students' Perceptions of Quality of School Life in Hong Kong Primary Schools. Educational Research Journal, 14(1), 49-71

Lukens, E. P. McFarlane, W. R. (2004). Psychoeducation as evidence-based practice: Consideration for practice, research, and policy. Journal Brief Treatment and Crisis Intervention, 4. Oxford University Press.

Muhammadi, N., Marzuki, S. C., \& Hussin, M. Y. M. (2015). The madrasah leadership, teacher performance and learning culture to improve quality at 
Caradde: Jurnal Pengabdian Kepada Masyarakat Vol 1 No 1, Agustus 2018

madrasah tsanawiyah negeri Jakarta of South. Journal of Management and Sustainability 5(2), 129-145.

Saraswati, L., Tiatri, S., \& Sahrani, R. (2017). Peran self-esteem dan school well-being pada resiliensi siswa SMK Pariwisata A. Jurnal Muara Ilmu Sosial, Humaniora, dan Seni, 1(2), 511-518

Sun-Keung, N. (1999). Students' perceptions of quality of school life in Hong Kong primary schools. Educational Research Journal 4(1). Retrieved from http://hkier.fed.cuhk.edu.hk/journal/wp -content/uploads/2010/06/erj_v14n1_4971.pdf

Tentang Madrasah Tsanawiyah Al-Mafatih. (2015).

Diunduh dari http://mtsalmafatih.blogspot.co.id/2015/ 02/tentang-madrasah-tsanawiyah-almafatih. html 